\title{
Antidrug antibodies against TNF-blocking agents: correlations between disease activity, hypersensitivity reactions, and different classes of immunoglobulins
}

\author{
This article was published in the following Dove Press journal: \\ Biologics: Targets and Therapy \\ 17 February 2015 \\ Number of times this article has been viewed
}

\section{Maurizio Benucci' \\ Francesca Li Gobbi' \\ Francesca Meacci² \\ Mariangela Manfredi² \\ Maria Infantino ${ }^{2}$ \\ Maurizio Severino ${ }^{3}$ \\ Sergio Testi ${ }^{3}$ \\ Piercarlo Sarzi-Puttini ${ }^{4}$ \\ Cristian Ricci ${ }^{5}$ \\ Fabiola Atzeni ${ }^{6}$}

'Rheumatology Unit, ${ }^{2}$ Immunology and Allergology Laboratory Unit, ${ }^{3}$ Allergy and Clinical Immunology Unit, Nuovo Ospedale S Giovanni di Dio, Florence, Italy; ${ }^{4}$ Rheumatology Unit, L Sacco University Hospital, Milan, Italy; ${ }^{5}$ Department of Epidemiology and Preventive Medicine, University of Regensburg, Regensburg, Germany; 'IRCCS Galeazzi Orthopedic Institute, Milan, Italy

Correspondence: Maurizio Benucci Rheumatology Unit, Azienda Sanitaria di Firenze, Hospital S Giovanni di Dio, 3 Via Torregalli, Florence 50 I43, Italy

Tel +39055 693233l

Fax +39055 6932306

Email maubenucci@tiscali.it
Abstract: Although anti-TNF drugs have changed the clinical course of rheumatoid arthritis (RA), survival rates and resistance-to-therapy data confirm that about $30 \%$ of RA patients fail to respond. The aim of this study was to evaluate the correlations between the development of antidrug antibodies, specific $\operatorname{IgG}_{4}$ antibodies against TNF inhibitors, and resistance to therapy in RA patients. This retrospective study involved 129 patients with established RA naïve to biological agents ( 98 females and 32 males, mean age 56.7 \pm 12.3 years, disease duration $6.3 \pm 1.2$ years, baseline Disease Activity Score [DAS]-28 3.2-5.6) who received treatment with anti-TNF agents after the failure of conventional disease-modifying antirheumatic drugs (32 received infliximab [IFX], 58 etanercept [ETN], and 39 adalimumab [ADA]). After 6 months of treatment, the patients were classified as being in remission (DAS28 <2.6), having low disease activity (LDA; DAS28 2.6-3.2), or not responding (NR: DAS28 >3.2). The patients were also tested for serum antidrug antibodies and $\mathrm{IgG}_{4}$ antibodies against TNF inhibitors. After 24 weeks of treatment, $38 \%$ of the ETN-treated patients and $28 \%$ of those treated with ADA had injection-site reactions; the rate of systemic reactions in the IFX group was $25 \%$. The differences among the three groups were not statistically significant $(P=0.382$; ETN versus ADA $P=0.319)$. The percentages of patients with adverse events stratified by drug response were: LDA $8 \%$ and NR $18 \%$ in the ADA group; in remission 3\%, LDA $22 \%$, and NR 10\% in the ETN group; and LDA $6 \%$ and NR $16 \%$ in the IFX group $(P=0.051)$. The percentages of patients with antidrug antibodies were: ADA $33.3 \%$, ETN $11.5 \%$, and IFX 10.3\% ( $P=0.025$; ADA versus ETN $P=0.015)$. The percentages of patients with $\mathrm{IgG}_{4}$ antibodies were: ADA 6\%, ETN 13\%, and IFX 26\% ( $P=0.017$; ADA versus ETN $P=0.437$ ). Associations between antidrug antibodies, specific $\mathrm{IgG}_{4}$ antibodies, and adverse reactions were not significant for any of the three drugs. $\mathrm{IgG}_{4}$ levels were higher in the ADA group than in the other two groups, and higher in the patients with worse DAS28 (NR) and in those experiencing adverse events. These data suggest a possible association between $\operatorname{IgG}_{4}$ levels and worse DAS28 $\left(r^{2}=5.8 \%, P=0.011\right)$. The presence of specific $\operatorname{IgG}_{4}$ antibodies against TNF blockers in patients with RA might affect the drugs' activity. Patients with injection-site reactions and $\mathrm{IgG}_{4}$ against ETN may show a decreased response.

Keywords: antidrug antibodies, TNF-blocking agents, $\operatorname{IgG}_{4}$ antibodies

\section{Introduction}

Over the last 20 years, biological therapies (especially TNF inhibitors) have revolutionized the management of chronic inflammatory diseases, including rheumatoid arthritis (RA). Disease management has been dominated by the three TNF inhibitors infliximab (IFX), adalimumab (ADA), and etanercept (ETN), but despite an acceptable response 
rate of $60 \%-70 \%$, a substantial proportion of patients fail to respond (primary failure) or experience significant side effects. ${ }^{1}$ Some questions have also arisen concerning the safety of TNF inhibitors, because they can trigger immunization, induce rare type I and III hypersensitivity, and cause acute and delayed reactions.

There have been many reports of reactions in patients receiving intravenous IFX, a chimeric $\operatorname{IgG}_{1 \mathrm{k}}$ anti-TNF agent, ${ }^{2}$ and immunomediated side effects, such as cutaneous reactions, have been encountered during therapy with subcutaneous anti-TNF drugs. One recent paper described injection-site reactions in $29.3 \%$ of patients treated with ETN. ${ }^{3}$ Adverse reactions to biological agents have been categorized into five types, including a complement-mediated reaction with immediate $\mathrm{IgE}$ or delayed $\mathrm{IgG}$ antibody formation. ${ }^{4}$ The immunoglobulin $\mathrm{IgG}_{4}$ is an IgG subtype that has been described by some authors (particularly Parish in the 1970s) ${ }^{5}$ as potentially causing transient sensitization that leads to signs and symptoms comparable with those induced by IgEmediated reactions; this was initially termed IgG short-term sensitizing by Parish, because upon passive transfer to normal skin, the sensitivity persists for only $2-4$ hours. IgG $_{4}$ differs from IgE insofar as it present in amounts that are large enough to be detected by agglutination or precipitation assays, and its sensitizing activity is not destroyed by heat or (in most cases) chemical reducing agents. ${ }^{4}$

All biological agents (whether of entirely human origin, chimeric, or "humanized") can cause an immune response, leading to the formation of antidrug antibodies (ADAbs), which are also known as human antichimeric antibodies or human antihuman antibodies, depending on the nature of the drug. The generation of ADAbs is increasingly recognized as a mechanism explaining the failure of anti-TNF drugs in chronic inflammatory diseases. The lack of a clinical response in patients with ADAbs may be due to the formation of an immune complex between TNF inhibitors and ADAbs that suppresses the drug and restricts its therapeutic activity. ${ }^{1}$

The aim of this study was to evaluate the correlations between the development of ADAbs and specific $\mathrm{IgG}_{4}$ antibodies against TNF inhibitors, adverse local and general hypersensitivity events, and resistance to therapy in RA patients.

\section{Materials and methods}

This retrospective study involved 129 patients with established RA naïve to biological agents (98 females and 32 males, mean age $56.7 \pm 12.3$ years, disease duration $6.3 \pm 1.2$ years, baseline Disease Activity Score [DAS]-28 scores 3.2-5.6) who received treatment with anti-TNF agents after the failure of conventional disease-modifying antirheumatic drugs: 32 (24.8\%) received IFX, 58 (44.9\%) ETN, and 39 (30.3\%) ADA. Table 1 shows their baseline characteristics.

After 6 months of treatment, the patients were classified as being in remission (DAS28 <2.6), having low disease activity (LDA; DAS28 2.6-3.2), or not responding (NR; DAS28 >3.2). During the 24 weeks of treatment, we also evaluated injectionsite reactions in patients treated with ETN or ADA, and systemic reactions in those treated with IFX.

The patients were tested for serum ADAbs with an antiTNF $\alpha$-blocker enzyme-linked immunosorbent assay kit (Immundiagnostik, Milan, Italy) and $\mathrm{IgG}_{4}$ antibodies against TNF inhibitors (fluoroenzyme immunoassay kit for ImmunoCap $^{\circledR} 250$; Phadia, Uppsala, Sweden). ADAb (Immundiagnostik) titers higher than $0.44 \mathrm{OD}$ for ETN, 0.18 OD for ADA, and 0.27 for IFX were considered positive. $\operatorname{IgG}_{4}$ antibodies against TNF inhibitors (ImmunoCap) higher than $5.9 \mathrm{mg}$ arbitrary unit/liter for ETA, $19.5 \mathrm{mg} \mathrm{A} / \mathrm{L}$ for ADA, and $8.6 \mathrm{mg} \mathrm{A} / \mathrm{L}$ for IFX were considered positive.

\section{Statistical analysis}

Power calculation was performed on correlation coefficients considering Fisher's Z-transformation, with an $\alpha$-value of 0.05 . For our simulation, we considered the following scenarios: a correlation coefficient ranging from 0.4 to 0.6 and a lower $95 \%$ confidence limit of the correlation coefficient (null correlation) ranging from 0.05 to 0.1 . In the more conservative scenario $\left(r_{\mathrm{sp}}=0.4\right.$ and null correlation of 0.1 ), we calculated that more than 90 subjects inclusive of up to $10 \%$ of missing values may be considered sufficient to achieve a nominal power over $90 \%$ (Figure S1).

Table I Characteristics of patients at baseline

\begin{tabular}{llll}
\hline & $\begin{array}{l}\text { Infliximab } \\
\mathbf{3 2} \text { patients }\end{array}$ & $\begin{array}{l}\text { Adalimumab } \\
\mathbf{3 9} \text { patients }\end{array}$ & $\begin{array}{l}\text { Etanercept } \\
\mathbf{5 8} \text { patients }\end{array}$ \\
\hline Age (years) & $52.3 \pm 12.2$ & $53.6 \pm \mathrm{I} 1.8$ & $54.5 \pm 12.9$ \\
Disease duration & $5.3 \pm 2.8$ & $5.5 \pm 3.1$ & $5.8 \pm 2.9$ \\
Rheumatoid & $76 \%$ & $78 \%$ & $75 \%$ \\
factor positivity & & & \\
APCA positivity & $81 \%$ & $79 \%$ & $78 \%$ \\
ESR, mm & $54.3 \pm 8.4$ & $55.7 \pm 7.2$ & $53.5 \pm 6.7$ \\
CRP, mg/dL & $3.2 \pm 1.7$ & $3.4 \pm 1.5$ & $3.7 \pm 1.4$ \\
DAS28 & $5.46 \pm 2.1$ & $5.43 \pm 1.9$ & $5.38 \pm 1.8$ \\
Corticosteroids & $6.1 \pm 1.2$ & $6.4 \pm 1.1$ & $6.3 \pm 1.2$ \\
dose, mg/day & & & $11.9 \pm 2.4$ \\
Methotrexate & $12.5 \pm 2.2$ & $12.1 \pm 2.1$ & \\
dose, mg/week & & & \\
\hline Abbreviations:APCA, & & & \\
\hline
\end{tabular}

Abbreviations: APCA, anti-citrullinated peptide/protein antibody; ESR, erythrocytesedimentation rate; CRP, C-reactive protein; DAS, Disease Activity Score. 


\section{Statistics revised}

Continuous variables were expressed as means \pm standard deviation and categorical variables were described by percentages. The $\chi^{2}$ test was used to compare categorical variables among groups, and the Pearson correlation coefficient was used to investigate for relations between quantitative variables. An $\alpha$-value of 0.05 was considered statistically significant, and all statistical tests were two-tailed. $\mathrm{IgG}_{4}$ levels were considered positive if superior to the following cutoff values: ETN 5.9, ADA 19.25, and IFX 8.6. ADAb levels were considered positive if superior to the following cutoff values: ETN 0.446, ADA 0.187, and IFX 0.275. Analyses were performed using Minitab16 software.

\section{Results}

After 24 weeks of treatment, $38 \%$ of the ETN-treated patients and $28 \%$ of those treated with ADA had injection-site reactions; the rate of systemic reactions in the IFX group was $25 \%$. The differences were not statistically significant ( $P=0.382$; ETN vs ADA $P=0.319$ ).

The percentages of patients with adverse events stratified by drug response were: LDA $8 \%$ and NR $18 \%$ in the ADA group; remission 3\%, LDA $22 \%$, and NR $10 \%$ in the ETN group; and LDA $6 \%$ and NR $16 \%$ in the IFX group ( $P=0.051)$. The percentages of patients with ADAbs were: ADA $33.3 \%$, ETN $11.5 \%$, and IFX $10.3 \%(P=0.025$; ADA vs ETN $P=0.015)$. The percentages of patients with $\mathrm{IgG}_{4}$ antibodies were: ADA 6\%, ETN 13\%, and IFX 26\% $(P=0.017$; ADA vs ETN $P=0.437)$. Associations between ADAbs, specific $\mathrm{IgG}_{4}$ antibodies and adverse reactions were not significant for any of the three drugs.

A scatter plot showed a positive correlation between $\mathrm{IgG}_{4}$ levels and worse DAS28, $\left(0.241, r^{2}=5.8 \% ; P=0.011\right.$; Figure 1). $\mathrm{IgG}_{4}$ quantities were higher in the ADA group than in the other two groups (Figure 2), but the correlation

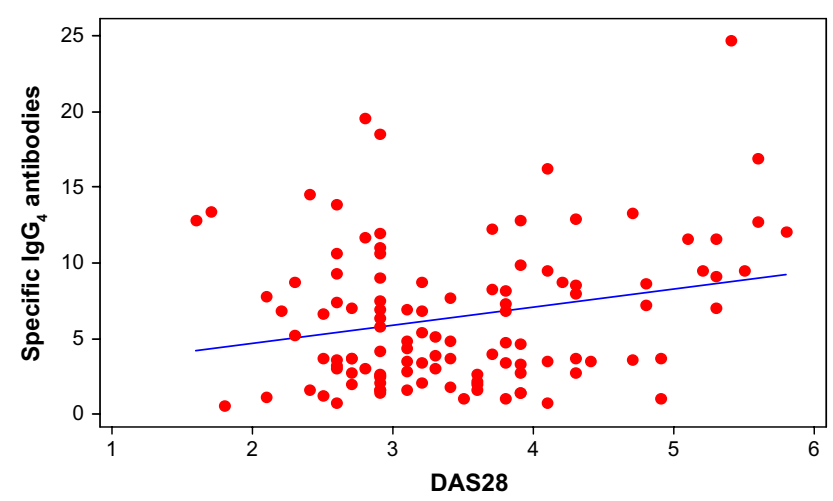

Figure I Scatter plot of specific $\operatorname{lgG}_{4}$ antibodies versus DAS28. Abbreviation: DAS, Disease Activity Score.

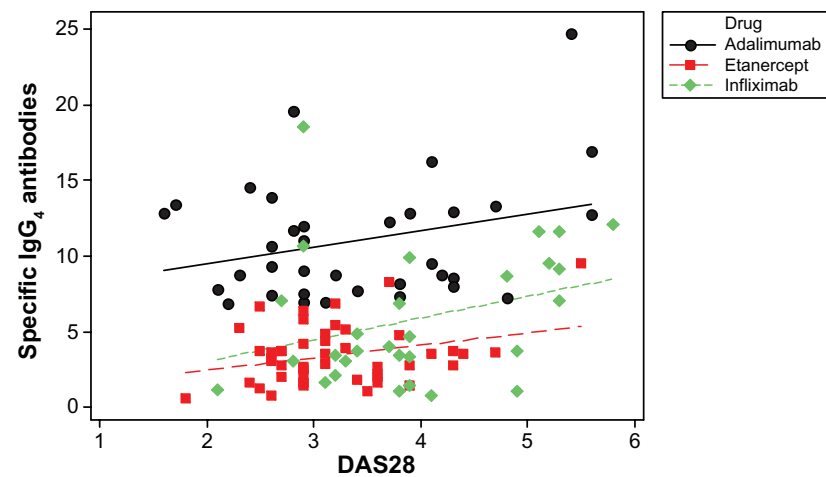

Figure $2 \operatorname{lgG}_{4}$ specific antibodies against three different TNF blocking agents and DAS28.

Abbreviation: DAS, Disease Activity Score.

with DAS28 was only significant for the ETN group, (ADA $0.287, P=0.094$; ETN 0.299, $P=0.039$; IFX 0.314, $P=0.097$ ). The correlation between ETN and DAS28 was consistent with the higher percentage of ETN patients positive for $\operatorname{IgG}_{4}$ (shown earlier) with respect to the ADA patients. There was a positive correlation between $\mathrm{IgG}_{4}$ levels (regardless of the drug group) in patients experiencing adverse events (Figure 3, red line and dots; subjects having experienced adverse events correlating with DAS28 value $=0.578$, $\left.r^{2}=33.5 \% ; P=0.000\right)$.

\section{Discussion}

Our results suggest that $\mathrm{IgG}_{4}$ may play a role in the adverse reactions and therapeutic response to biological agents of patients with RA. The role of anti-ADA $\operatorname{IgG}_{4}$ was first detected by means of an immunoassay in 271 consecutive RA patients during 3 years of treatment: anti-ADA antibodies were detectable in $32 \%$, and specific $\mathrm{IgG}_{4}$ antibodies in $29 \%$. Although $\mathrm{IgG}_{4}$ is often considered to be harmless due to its lack of an effector function, the neutralization of ADA by specific $\operatorname{IgG}_{4}$ antibodies leads to a reduced clinical response. ${ }^{6}$

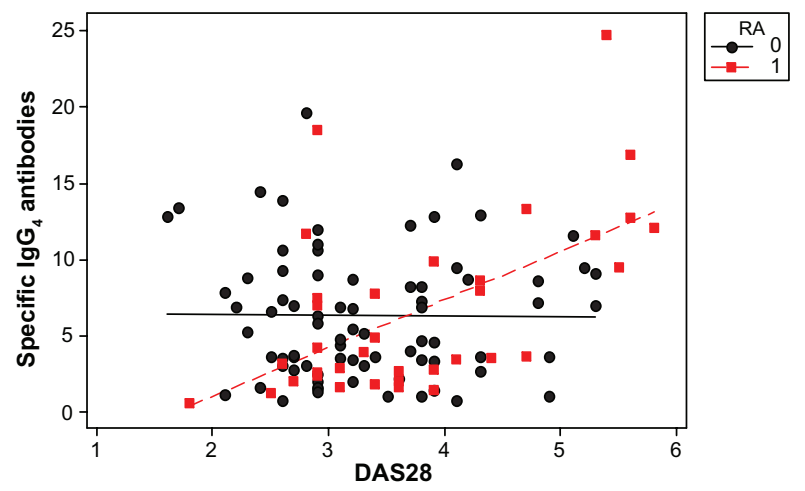

Figure 3 Correlation between $\lg G_{4}$ specific antibodies, adverse effects and DAS28. Abbreviations: DAS, Disease Activity Score; RA, rheumatoid arthrirtis. 
In our 24-week study, we detected ADAbs in 33.3\% of our ADA patients and $\mathrm{IgG}_{4}$ in only $6 \%$.

Approximately $4 \%$ of the total $\mathrm{IgG}$ in the serum of Caucasian adults is $\mathrm{IgG}_{4}{ }^{7}$ which is considered an odd antibody insofar that it is the only IgG unable to activate complement and has a low affinity for Fc $\gamma$ receptors. ${ }^{8,9}$ Furthermore, it is able to exchange half-molecules in vivo, thus leading to bispecific antibodies that do not cross-link and the consequent formation of small immune complexes. ${ }^{10,11}$ Because of its limited ability to trigger immunological effector functions and its tendency to form small immune complexes, it is thought that $\mathrm{IgG}_{4}$ has less effect on the clearance of antigens and plays a limited role in inflammation.

Although the percentage of serum $\operatorname{IgG}_{4}$ is generally low, antigen-specific $\mathrm{IgG}_{4}$ has been described as the main isotype produced in some immune responses. As early as the 1970s, it was shown that chronic antigen exposure to grass pollen and bee venom led to the predominant formation of $\mathrm{IgG}_{4},{ }^{12}$ and increased allergen-specific $\operatorname{IgG}_{4}$ is associated with a beneficial response to specific allergen immunotherapy in allergic patients. ${ }^{13,14}$ Chronic treatment with biological agents, such as factor VIII, IFN $\beta$, or therapeutic monoclonal antibodies can be considered long-term exposure to protein antigens. There have been frequent reports of the formation of $\mathrm{IgG}$ antibodies against biological agents, some of which have been found to produce $\mathrm{IgG}_{4}$. Prolonged exposure to IFN $\beta$ can also lead to the development of $\mathrm{IgG}_{4}$ antibodies in patients with multiple sclerosis, ${ }^{15}$ but although it has been shown that therapeutic monoclonal antibodies can give rise to the formation of $\mathrm{IgG}_{4}$, there is lack of long-term measurements. ${ }^{16,17}$ The observation that the proportion of $\mathrm{IgG}_{4}$ antibodies may diminish over time is somewhat unusual, and differs from what has been described in the various allergens. ${ }^{18}$

Our results showed more injection-site reactions in the ETN group than in the ADA group (38\% vs 28\%), and the presence of anti-ETN IgG $_{4}$ in $13 \%$ of the patients. Although it is not yet known what factors induce class switching to $\mathrm{IgG}_{4}$, it can be speculated that the immunological context of the patients and/or the intensity of treatment (dosing and frequency) may play a role. One of the reasons for the difference in $\mathrm{IgG}_{4}$ responses between ADA-treated and allergic patients may be that the former received $40 \mathrm{mg}$ every 2 weeks, whereas the patients receiving allergen-specific immunotherapy received $20 \mu \mathrm{g}$ of allergen twice a week. The frequency of treatment could also explain the increase in anti-ETN $\operatorname{IgG}_{4}$.

Our findings indicate a correlation between adverse drug reactions and a poor response, and suggest that anti-ETN
$\mathrm{IgG}_{4}$ may have a decreased response to ETN therapy. Other studies have shown that the formation of anti-ADA antibodies is related to lower functional drug levels and a diminished clinical response. ${ }^{19,20}$ A large proportion of these antibodies are $\mathrm{IgG}_{4}$ antibodies, which suggests $\mathrm{IgG}_{4}$ is not simply an innocent bystander in this case. ${ }^{21}$ Although $\mathrm{IgG}_{4}$ antibodies cannot activate complement and have a low affinity for Fc receptors, they may still be able to compete with druginduced TNF $\alpha$ binding to drugs, thus leading to a clinical nonresponse.

We detected anti-ADA antibodies more frequently than anti-ETN antibodies ( $33 \%$ vs $11.5 \%$ ), whereas the rate of detection of $\mathrm{IgG}_{4}$ anti-ETN was $13 \%$, which may predict a lower response to ETN therapy in patients with injection-site reactions. One limitation of this study is that it did not measure the serum levels of the three drugs. Our study confirms that patients with injection-site reactions and anti-ETN IgG $_{4}$ may not respond to ETN therapy.

\section{Acknowledgment}

The study was supported by the Rheumatology Unit of the Nuovo Ospedale S Giovanni di Dio, Florence, Italy.

\section{Author contributions}

MB and FA designed the study and drafted the paper. MM, MI, and FM performed the laboratory analysis. FLG and MB recruited the patients. PSP commented on and critically edited the paper. All authors contributed toward data analysis, drafting and revising the paper and agree to be accountable for all aspects of the work.

\section{Disclosure}

The authors report no conflicts of interest in this work.

\section{References}

1. Vincent FB, Morand EF, Murphy K, Mackay F, Mariette X, Marcelli C. Antidrug antibodies (ADAb) to tumour necrosis factor (TNF)-specific neutralising agents in chronic inflammatory diseases: a real issue, a clinical perspective. Ann Rheum Dis. 2013;72:165-178.

2. Cheifetz A, Smedley M, Martin S, et al. The incidence and management of infusion reactions to infliximab: a large center experience. Am J Gastroenterol. 2003;98:1315-1324.

3. Dore RK, Mathews S, Schechtman J, et al. The immunogenicity, safety, and efficacy of etanercept liquid administered once weekly in patients with rheumatoid arthritis. Clin Exp Rheumatol. 2007;25:40-46.

4. Pichler WJ, Campi P. Adverse side effects to biological agents. In: Pichler WJ, editor. Drug Hypersensitivity. Basel: Karger; 2007: 160-174.

5. Parish WE. Short term anaphylactic IgG antibodies in human sera. Lancet. 1970;19;2(7673):591-592.

6. van Schouwenburg PA, Krieckaert CL, Nurmohamed M, et al. IgG4 production against adalimumab during long term treatment of RA patients. J Clin Immunol. 2012;32:1000-1006. 
7. Aalberse RC, van der Gaag R, van Leeuwen LJ. Serologic aspects of IgG4 antibodies. I. Prolonged immunization results in an IgG4-restricted response. J Immunol. 1983;130:722-726.

8. Tao MH, Canfield SM, Morrison SL. The differential ability of human IgG1 and IgG4 to activate complement is determined by the COOH-terminal sequence of the CH2 domain. J Exp Med. 1991;173: 1025-1028.

9. Nirula A, Glaser SM, Kalled SL, Taylor FR. What is IgG4? A review of the biology of a unique immunoglobulin subtype. Curr Opin Rheumatol. 2011;23:119-124.

10. Van Der Zee JS, Van Swieten P, Aalberse RC. Serologic aspects of IgG4 antibodies. II. IgG4 antibodies form small, nonprecipitating immune complexes due to functional monovalency. J Immunol. 1986;137: 3566-3571.

11. van der Neut KM, Schuurman J, Losen M, et al. Anti-inflammatory activity of human IgG4 antibodies by dynamic Fab arm exchange. Science. 2007;317:1554-1557.

12. van der Giessen M, Homan WL, van Kernbeek G, Aalberse RC, Dieges PH. Subclass typing of $\mathrm{IgG}$ antibodies formed by grass pollen-allergic patients during immunotherapy. Int Arch Allergy Appl Immunol. 1976;50:625-640.

13. Gehlhar K, Schlaak M, Becker W, Bufe A. Monitoring allergen immunotherapy of pollen-allergic patients: the ratio of allergen-specific IgG4 to IgG1 correlates with clinical outcome. Clin Exp Allergy. 1999;29: 497-506.

14. Nouri-Aria KT, Wachholz PA, Francis JN, et al. Grass pollen immunotherapy induces mucosal and peripheral IL-10 responses and blocks IgG activity. J Immunol. 2004;172:3252-3259.
15. Deisenhammer F, Reindl M, Berger T. Immunoglobulin subclasses in patients with neutralizing and non-neutralizing antibodies against IFN-ß1b. J Interferon Cytokine Res. 2001;21:167-171.

16. Svenson M, Geborek P, Saxne T, Bendtzen K. Monitoring patients treated with anti-TNF-alpha biopharmaceuticals: assessing serum infliximab and anti-infliximab antibodies. Rheumatology (Oxford). 2007;46:1828-1834.

17. Wouters D, Stapel S, Vis M, et al. Human antichimeric antibodies to infliximab and infusion-related allergic reactions in patients with rheumatoid arthritis. Allergy Clin Immunol Int. 2007;2:198-200.

18. Aalberse RC, Stapel SO, Schuurman J, Rispens T. Immunoglobulin G4: an odd antibody. Clin Exp Allergy. 2009;39:469-477.

19. van Kuijk AW, de Groot M, Stapel SO, Dijkmans BA, Wolbink GJ, Tak PP. Relationship between the clinical response to adalimumab treatment and serum levels of adalimumab and anti-adalimumab antibodies in patients with psoriatic arthritis. Ann Rheum Dis. 2010;69:624-625.

20. Bartelds GM, Wijbrandts CA, Nurmohamed MT, et al. Clinical response to adalimumab: relationship to anti-adalimumab antibodies and serum adalimumab concentrations in rheumatoid arthritis. Ann Rheum Dis. 2007;66:921-926.

21. Bartelds GM, Krieckaert CL, Nurmohamed MT, et al. Development of antidrug antibodies against adalimumab and association with disease activity and treatment failure during long-term follow-up. JAMA. 2011;305:1460-1468. 


\section{Supplementary material}

Correlation $=0.5$ null correlation $=0.1$

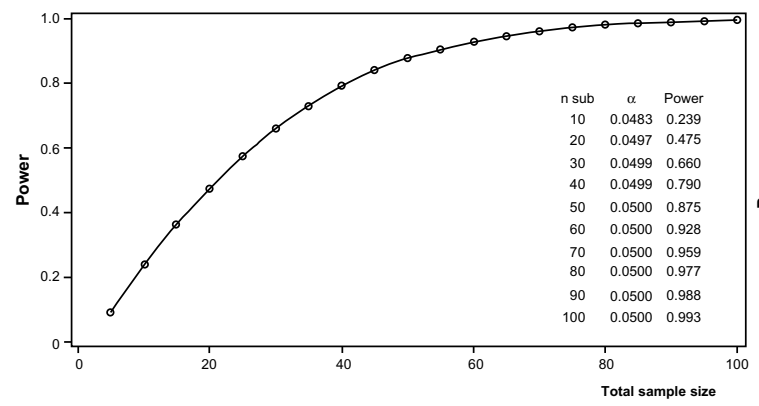

Correlation $=0.4$ null correlation $=0.1$

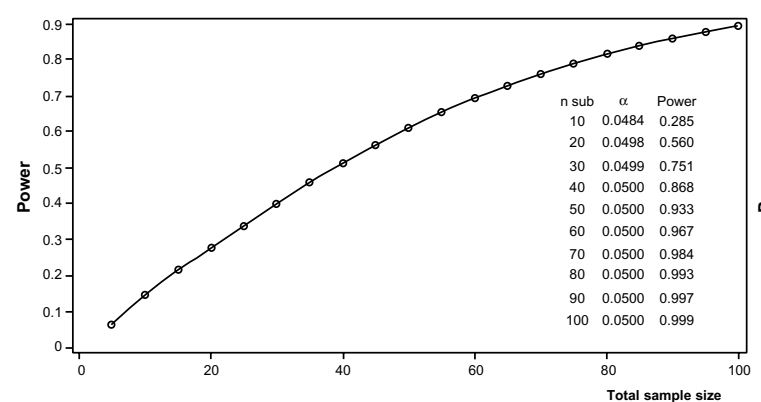

Correlation $=0.6$ null correlation $=0.1$

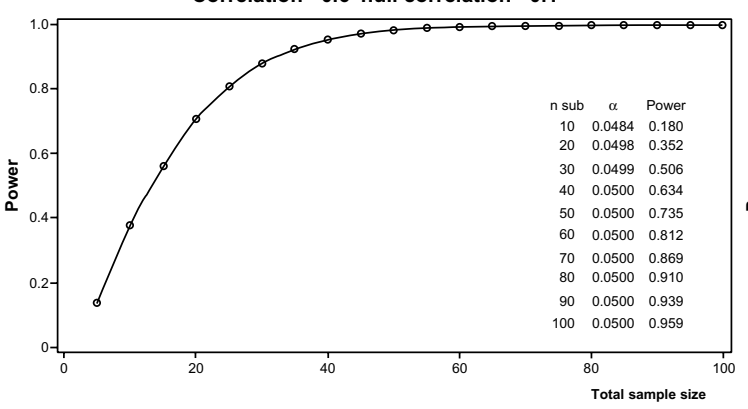

Correlation $=0.5$ null correlation $=0.05$

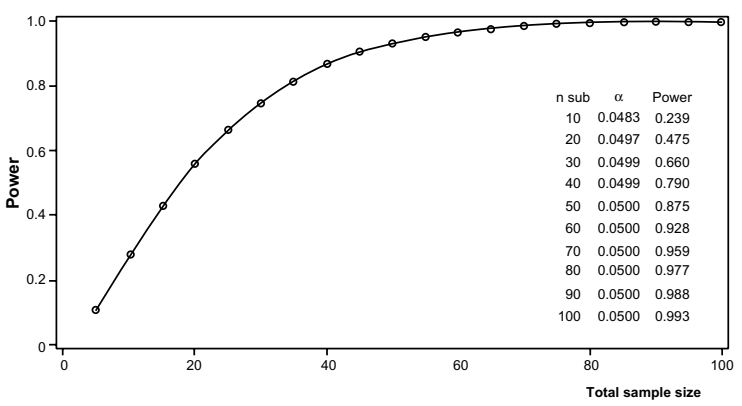

Correlation $=0.4$ null correlation $=0.05$

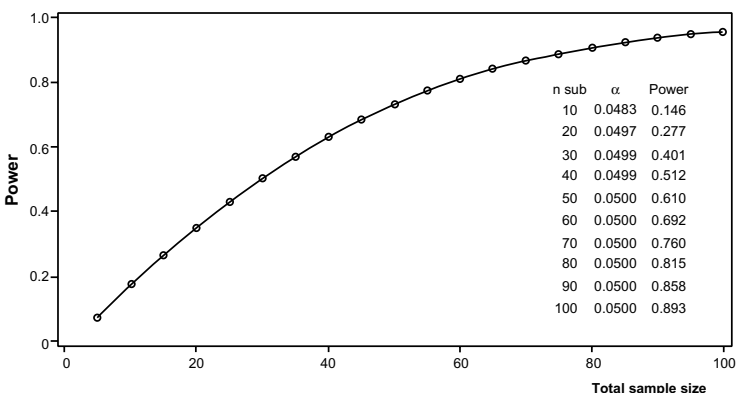

Correlation $\mathbf{0} \mathbf{0 . 6}$ null correlation $\mathbf{= 0 . 0 5}$

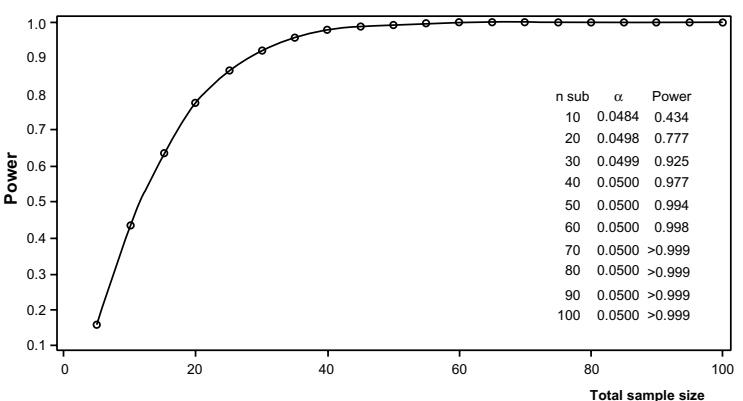

Figure SI Power calculations.

Notes: Power calculation reporting power (I-beta) vs sample size (number of pairs) under the assumption of a correlation coefficient ranging from 0.4 to 0.6 (moderate weak to moderate strong) with a null correlation of 0.1 and 0.05 for the left and the right panels respectively.

\section{Dovepress}

\section{Publish your work in this journal}

Biologics: Targets \& Therapy is an international, peer-reviewed journal focusing on the patho-physiological rationale for and clinical application of Biologic agents in the management of autoimmune diseases, cancers or other pathologies where a molecular target can be identified. This journal is indexed on PubMed Central, CAS, EMBase, Scopus and the Elsevier Bibliographic databases. The manuscript management system is completely online and includes a very quick and fair peerreview system, which is all easy to use. Visit http://www.dovepress. com/testimonials.php to read real quotes from published authors. 